\title{
'I Wish Someone Would Ask Me Questions': The Unheard Voices of Adolescents with Disabilities in Jordan
}

\author{
Kifah Bani Odeh ${ }^{1} \cdot$ Nicola Jones $^{2} \cdot$ Kate Pincock $^{3}$ (D) $\cdot$ Agnieszka Malachowska $^{1}$
}

Accepted: 28 May 2021 / Published online: 15 September 2021

(c) The Author(s) 2021

\begin{abstract}
The Sustainable Development Goals and the Leave No One Behind agenda involve a commitment to ensure the participation of persons with disabilities in all aspects of family and community life. This article explores the experiences of Palestinian and Syrian refugee adolescents with disabilities in Jordan in two domains of life: access to education, and their capacity to exercise voice and agency. The findings show that disability intersects with citizenship status and place of residence (camp vs village or city alongside the host community) to reinforce marginality for certain groups of adolescents with disabilities. Across the board, we find low educational aspirations and learning outcomes among adolescents with disabilities, and markedly lower social connectivity-but greater risk of violence by peers. To address these unequal outcomes, we reflect on the importance of developing more inclusive formal and non-formal education services to promote the participation of adolescents with disabilities, and investments in better training and awareness raising for parents, teachers and peers alike.
\end{abstract}

Keywords Adolescents · Disability · Education · Social connectivity · Violence · Refugees

Kate Pincock

k.pincock.gage@odi.org

Kifah Bani Odeh

kifah_odeh@hotmail.com

Nicola Jones

n.jones@odi.org.uk

Agnieszka Malachowska

a.malachowska@odi.org.uk

1 GAGE, Mena, UK

2 ODI, London, UK

3 University of Oxford, Oxford, UK 


\section{Résumé}

Les objectifs de développement durable (ODD) et le programme Ne laisser personne de côté comprennent un engagement à garantir la participation des personnes handicapées à tous les niveaux de la vie familiale et communautaire. Cet article explore les expériences des adolescents et adolescentes réfugié.es palestinien.nes et syrien. nes handicapé.es en Jordanie dans deux domaines de la vie: l'accès à l'éducation et leur capacité à faire entendre leur voix et à agir. Les résultats montrent que le handicap se trouve à l'intersection avec le statut de citoyenneté et le lieu de résidence (un camp plutôt qu'un village ou une ville proche de la communauté d'accueil) et vient renforcer la marginalité de certains groupes d'adolescent.es handicapé.es. Dans l'ensemble, nous constatons qu'il y a de faibles aspirations éducatives et de faibles résultats en terme d'apprentissage chez les adolescent.es handicapé.es, ainsi qu'une connection sociale nettement plus faible - tout en notant un risque plus élevé de violence par les pairs. Afin de remédier à ces inégalités, nous menons une réflexion sur l'importance de développer des services d'éducation formelle et non formelle plus inclusifs pour promouvoir la participation des adolescents et adolescentes handicapé. es, et sur la nécessité d'investir pour mieux former et mieux sensibiliser les parents, les enseignants et les pairs.

\section{Introduction}

Disability and poverty are linked in a 'vicious circle' that has been well established in the extant literature (Yeo and Moore 2003; Braithwaite and Mont 2009; Palmer 2011). Disability can exacerbate poverty because it limits access to education and employment opportunities (Ingstad and Eide 2011). Marginalisation has other consequences too, including greater risk of psychosocial problems such as stress, depression and low confidence (Jones et al. 2018).

While the Millennium Development Goals (MDGs) failed to directly address disadvantages associated with disability, the Sustainable Development Goals (SDGs)' commitment to leave no one behind highlights the need to dismantle structures that reproduce marginalisation of persons with disabilities. If development is to be truly inclusive and equitable, efforts must be made to dismantle barriers facing people with disabilities that prevent their participation (WHO and World Bank 2011; Hashemi et al. 2017). In recognition of this, people with disabilities are explicitly mentioned in five of the SDGs, around quality education, decent work and economic growth, reduced inequalities, sustainable cities and communities, and partnerships for meeting the goals.

Measures of multidimensional poverty highlight that disability can intersect with other forms of disadvantages such as gender and age to compound experiences of social exclusion (Alkire et al. 2015). As young people go through adolescence, gender norms become more rigidly enforced by families, communities and peers, with the result that girls' worlds become smaller as their behaviour and social lives are increasingly restricted (Marcus and Harper 2015). Girls with disabilities face the additional constraint of disability-related stigma, which limits their opportunities for participation and agency (Jones et al. 2018). However, there is a dearth of 
gender- and age-disaggregated data on disability to inform policy and practice (Ingstad and Eide 2011). Indeed, the prevalence of disability among children and adolescents globally is unknown; estimates vary widely, from 93 to 150 million, with $80 \%$ thought to be living in low- and middle-income countries (LMICs) and below national poverty lines (WHO and World Bank 2011).

Adolescents with disabilities are more likely than their peers to be 'left behind' in many aspects. They are less likely to be in school as they advance through grades such that the education gap between adolescents with and without disabilities is actually worsening over time (Male and Wodon 2017). This has longer-term consequences for their income as adults; this not only brings significant economic costs but is also a human rights issue (WHO and World Bank 2011). In 1994, the Salamanca Statement that calls for inclusive education which responds to the needs of all learners and aims for integration of people with disabilities in mainstream schooling was ratified by 92 countries, and informs Article 24 of the United Nations Convention on the Rights of People with Disabilities (UNCRPD). The UNCRPD affirms inclusive education and lifelong learning as inherent to human dignity, selfworth and the realisation of one's potential, as well as their effective participation in society (UNCRPD 2006). However, there remains a lack of clarity about how to achieve inclusive education in practice, and in lower- and middle-income countries, under-resourcing of education systems and limited teacher training hampers efforts to achieve policy objectives (Anastasiou and Keller 2011; Benson 2020). In many contexts, inclusive education is still associated with disability, rather than as a practice of ensuring a supportive learning environment for all students according to their needs, leading to an emphasis on 'specialised' schools rather than integration of learners (Srivastava et al. 2013).

Adolescents with disabilities also face severe restrictions on their agency. Access to agency is conceptualised here as adolescents' physical freedom of movement, access to age-appropriate information and meaningful participation in decisions which shape their lives (Jones et al. 2019). Due to concerns about their safety or a lack of adaptations and support for their mobility, the social lives of adolescents with disabilities are limited, often with profound mental health impacts. This is exacerbated by their vulnerability to bullying; adolescents with disabilities are three to four times more likely to experience violence than their peers without disabilities and are often targeted for violence from their peers (Jones et al. 2012). This has multiple and long-term consequences for both their mental and physical health. One of the main contributors to loss of disability-adjusted life years (DALYs) worldwide for adolescents - for both boys and girls - are mental health disorders (Patton et al. 2016). The link between positive mental health and feeling valued by one's family and peers is acknowledged by research in various contexts (Mustafa et al. 2015). Yet often, this is not available to adolescents with disabilities due to the stigma and isolation they face. Poor mental health as a result of victimisation or neglect by communities is exacerbated by the lack of services available offering support to adolescents with disabilities (Jones et al. 2018).

In contexts of displacement, these structural vulnerabilities are heightened. While $15.3 \%$ of the world's people have a moderate or severe disability, rates in conflictaffected populations are likely to be closer to 20\% (WHO and World Bank 2011). 
Not only can conflict cause disabilities, but people with disabilities face increased risk of abandonment and separation from families or support structures, as well as loss of mobility and assistive devices, and difficulties accessing information (Rohwerder 2017). They are also at greater risk of poor mental health due to the trauma of displacement, and at greater risk of abuse and exploitation. However, programming in humanitarian contexts has tended to focus on health needs rather than schooling, shelter, livelihoods and protection (Pearce 2015). Assistance tends to be directed to those with visible impairments (such as amputations and motor difficulty) rather than people with less visible impairments (such as cognitive disabilities, for example) (Battle 2015).

Despite recognition that adolescence is a crucial time of social transition and expansion of capabilities, there is a dearth of research that attends to the experiences of adolescents with disabilities. This article engages with this knowledge gap as it draws on research with displaced and host community adolescents with disabilities in Jordan, where adolescents ordinarily have limited opportunities to participate in society (Jones et al. 2018), compounded by inequalities rooted in disability, gender and place of residence (camp vs village or city within the host community). Jordan also hosts significant numbers of refugees, mostly from Syria and Gaza, who are known to have high rates of physical disability (Skinner 2014; Thompson 2020). The Global Burden of Disease study highlights that DALYs for adolescents and children in conflict-affected Syria have become notably worse in recent times, with injury rates for those aged under 20 rising by 562\% since 1990 (GBD 2017 Child and Adolescent Health Collaborators 2019). Gazan Palestinians have lived through protracted displacement in Jordan (for decades), but lack citizenship rights and identity documents (ID), which precludes them from accessing services and labour markets. Syrian refugees, most of whom arrived after the civil war in their country began (2011), receive limited support from the United Nations Refugee Agency (UNHCR) (Humanity \& Inclusion and iMMAP 2018). This article therefore draws comparisons across three groups of adolescents with disabilities living in Jordan: stateless Palestinians, Syrian refugees and Jordanian nationals.

This paper draws on qualitative data generated as part of a larger mixed-methods study in Jordan under the Gender and Adolescence: Global Evidence (GAGE) programme, which explores 'what works' in expanding adolescent capabilities. We focus on two related capability domains of relevance to the SDGs: adolescents with disabilities' experiences of education (SDG 4); and their capacity to exercise voice and agency (captured in SDG 10, on reducing inequalities, and SDG 17, on partnerships for the goals). Drawing also on a social model of disability-which emphasises that it is society that imposes disability on individuals with impairments (Mitra 2006) and that structural solutions are needed to address their poorer outcomeswe explore how stigma, marginalisation and discrimination have tangible effects on adolescents' outcomes in relation to education, and voice and agency. These factors are compounded by gender norms, which put adolescent girls with disabilities at greater risk of capability deprivations, and by differences based on nationality and place of residence (camp vs host community), which can either intensify or ameliorate social stigma and marginality. 


\section{Background}

Jordan is a signatory to the UNCRPD, and over the years has implemented legislation aimed at promoting an inclusive education system and the rights of people with disabilities, including most recently the 2017 Law on the Rights of Persons with Disabilities, which emphasises educational rights. Yet, a body of research problematises government efforts to make education inclusive of adolescents with disabilities, pointing to a lack of funding, accountability and coordination that undermines effective implementation of legislation (Al-Zyoudi 2006; El-Zraigat and Smadi 2012; Abu-Hamour and Al-Hmouz 2014; Presler-Marshall et al. 2020; Benson 2020). Furthermore, because of the stigma around disability in Jordan, families are reluctant to disclose that their children have any impairments, and particularly so for daughters (AlMakhamreh et al. 2015). This means disability is often under-reported and inadequately discussed, making it challenging for policy to respond to the needs of young people with disabilities. Indeed, previous research in multiple contexts has indicated that because public support for disability-inclusive policies is essential for success, attitudinal barriers can be an even bigger obstacle than material barriers like resources and infrastructure (Avramidis and Norwich 2002; Burge et al. 2008; Scior 2011).

Jordan's political environment creates particular challenges for young refugees with disabilities, who tend to be treated as homogenous in policies 'with little or no alertness to context, culture, religion, gender, but especially dis/ability' (Pisani and Grech 2015, p. 422). Gender also mediates experiences of marginalisation among refugees with disabilities; in other contexts, research has found that stereotyping and stigma lead to different treatment of boys and girls by those who interact with them in educational settings (Vilchinsky et al. 2010; Bešić et al. 2020). However, despite the many Palestinian and Syrian adolescent refugees with disabilities living in Jordan, and the government's efforts to make schools more inclusive (both of refugees and learners with disabilities), previous research has not explored the perspectives of young refugees with disabilities in this context.

We do know that older Syrian refugee children in Jordan express the highest levels of fear, depression and anxiety of all young people, and particularly in camps like Zaatari, where refugees have experienced violence first-hand (Jabbar and Zaza 2014). Education, which can offer a safe space for young people in emergency settings, is often advocated (ibid.), yet the scale of Syrian displacement means that schools in Jordan are oversubscribed and under-resourced, leading to practical and material challenges for making them more inclusive (Culbertson and Constant 2015). Lack of public transportation means families are often reluctant to send children they consider to be more at-risk to school (International Network for Education in Emergencies 2014). These dynamics present major obstacles for access to education for refugee adolescents with disabilities in Jordan.

Extant literature on disability and global health also highlights the pressing need for investment to attend to the multiple and long-term mental and physical health impacts experienced by adolescents with disabilities. Yet there is little research on the relationship between disability and displacement; nor has there been significant 
work on disability in Jordan to explore adolescents' experiences or how gender intersects with other social identities. These are, however, important issues to understand in more depth, because of the scale of the refugee crisis in Jordan and high numbers of adolescents living with disabilities in both host communities and camps. The oversubscription of support services means that adolescents with disabilities are at high risk of being left behind by current approaches.

\section{Conceptual Framing}

This research was undertaken as part of the Gender and Adolescence: Global Evidence (GAGE) programme in 2018 and 2019. The GAGE conceptual framework draws on Amartya Sen's capabilities approach $(1985,1999)$, which emphasises that human beings need certain human, political, social, emotional and economic assets and resources to lead lives that they value. A capabilities approach is particularly useful for research with adolescents with disabilities because it recognises that having an impairment affects the resources and assets one needs to live a life that one values, but also that this is not the only source of limitations. Characteristics like age or citizenship status also affect one's ability to fulfil certain capabilities, as does the broader physical and material environment (Burchardt 2004). Recognising this, GAGE sees an individual's capacity to achieve different capabilities as just one of three interconnected dimensions (the ' $3 \mathrm{Cs}$ ) that shape adolescents' trajectories - the other two being change strategies and contexts. Change strategies refer to the policy and programming interventions needed to improve outcomes in these capability domains, while context refers to the effects of local, national and international dynamics on adolescents' capabilities. An approach that accounts for these three dimensions and the ways they intersect is essential for tackling the challenge of developing effective interventions with adolescents with disabilities.

In analysing the experiences of adolescents with disabilities in Jordan, the GAGE conceptual framework can be complemented by literature on the social model of disability, as both approaches prioritise societal barriers to equality and emphasise the central role of discrimination (Burchardt 2004). The social model of disability does, however, qualify the capabilities approach. As Baylies argues, the capabilities approach risks presenting disability as a fixed category, obscuring the fact that 'very few of us qualify as fully able-bodied, along all dimensions of functioning, throughout all of our lives' (Baylies 2002, p. 736). The social model of disability also underscores the right of people with disabilities to 'self-determine' rather than have their rights, needs and health status defined by others. This emphasis is reflected in the attention paid in this article to the voice and agency of adolescents with disabilities, including opportunities to contribute to decision-making within their families that affects their lives, and their participation in their communities such as playing sports or socialising with their neighbours. This approach aligns particularly well with the data on which our article draws, which centres voice and agency, and counters the dearth of research that engages directly with the perspectives of adolescents with disabilities on what they want from their lives, and what they need to achieve this. 


\section{Methodology}

GAGE conducted research with Jordanian and Syrian refugee adolescents in three sites: Amman, the capital; Irbid, a governorate whose main city is the second largest after Amman; and Mafraq, a rural governorate. The research included Syrian adolescents in Zaatari and Azraq camps and those living in informal tented settlements (ITSs), and young people from stateless Palestinian communities in Jerash refugee camp. There are significant differences in levels of provision of education and community activities for adolescents with disabilities across these sites, and important differences in how people with disabilities are regarded. These factors affect adolescents' experiences of education and their voice and agency in various ways.

Data were collected between August and December 2018, through in-depth interviews with 56 adolescents with disabilities aged 10-12 and 15-17, and 26 interviews with caregivers of younger children (see Table 1 for a breakdown of the sample by age, gender and type of impairment). Interviews were transcribed, translated and coded using MAXQDA software. Researchers were bilingual in English and Arabic, and a back translation was used for verification. Thematic analysis was done by three researchers, using a codebook developed based on the sub-domain indicators mapped out in the GAGE conceptual framework (GAGE Consortium 2019). This was then further adapted based on formative research with young people with disabilities in Jordan undertaken in 2016 and 2017 to ensure contextual relevance.

In the sample, a balance of young people with visual, hearing and physical impairments, male and female, young and older adolescents and those attending specialist education and those who are in mainstream education was sought. We used a snowballing technique following recommendations of NGOs and CBO providers. Safeguarding measures included a clear process for obtaining fully informed consent (and assent where appropriate depending on age), and conducting interviews with adolescents in their homes, in a place chosen by them, and where possible at the same time as caregivers were being interviewed to give each respondent more privacy. Intensive training was provided to the researchers by expert researchers and disability advocates in Jordan as to how they could support participation in the research on a case-by-case basis, and a range of tools were used during interviewing to reflect the diverse strengths and interests of participants. This often led to rich insights, as well as making participants more comfortable with researchers. A

Table 1 Qualitative sample breakdown

\begin{tabular}{lllllll}
\hline Individual interviews & \multicolumn{1}{l}{} & & & \\
\hline Adolescents & & & & & \\
Type of impairment & Boys 10-12 & Girls 10-12 & Boys 15-17 & Girls 15-17 & Mothers & Total \\
\hline Hearing & 3 & 4 & 3 & 8 & 7 & 25 \\
Visual & 8 & 4 & 5 & 6 & 11 & 34 \\
Physical & 4 & 4 & 3 & 4 & 8 & 23 \\
Total & 15 & 12 & 11 & 18 & 26 & 82 \\
\hline
\end{tabular}


referral process was also established and actively follow-up on for any safeguarding concerns noted during interviews. Ethical approval for the research was secured from the ODI Research Ethics Committee and from UNHCR Jordan.

\section{Findings}

\section{Education}

\section{Jordanian Adolescents}

Adolescents with disabilities living in Amman have much better access to education than those in Mafraq. Those with mobility impairments are able to attend schools which have accessibility adapted learning environments, and there are specialist private schools for those who can afford them. There are government-run schools for those with hearing impairments and a number of charitable societies that support schools with specially trained teaching staff. There are also other schools for children with hearing impairments in the vicinity of Amman city, including a school in Azraq city, which offers free transport to students. The main school for visually impaired children in Jordan is in Amman and is run by the government; Jordanian children from 1st to 12th grade across all governorates are entitled to enrol. To reduce attendance barriers, within Amman, a free bus picks up students, and children from other governorates who cannot travel each day can board at the school for free.

In this and other government-run schools for children with hearing and visual impairments, students have a track record of success in secondary (Tawjihi) examinations. One 18-year-old boy with severe visual impairments said, 'I had great success in Tawjihi-I got 74\%. I like English, and I plan to go and study English language'. Indeed, Jordanian children with disabilities reported high educational aspirations, with many planning to continue to secondary and university levels. A 13-year-old girl with a visual impairment said she was top in her class in her private school. 'I am the only one who is blind in the whole school, but I work hard to be remarkable. I will study at university once I am 18. I work to prove to my teachers that I am a good, hardworking person'.

In Irbid city, located in Irbid governorate, educational access is reasonable; there is a school for young people with hearing disabilities, though overall, services are less inclusive than in Amman. There is no school for blind children; they must instead go to Amman for specialist education provision. Good-quality education is available in Irbid, primarily because due to the size of villages, teachers tend to be relatives and friends of families with children who have disabilities and therefore want to include the children in school activities. The mother of a girl with a speech impairment explained how her daughter's teacher had included her in class, and found ways to make her daughter feel supported by her peers. 'The teacher wrote to me personally about my daughter's homework, so when my daughter came home, I was able to help her by going over the questions orally and encouraging her speech. I recorded her speaking and the teacher showed her 
class the video. This encouraged my daughter to like school'. The mother of a girl with a mobility impairment explained that 'the teachers are good and all girls in the class are all our relatives, so she has got good support at school'.

While Jordanian adolescents with disabilities in Irbid generally have better access to education than refugees, the supportive environment noted by Jordanians there even extended to Syrian refugees living in the villages. Our findings suggest that this is because people have been able to get to know each other better in these smaller communities, so are more willing to help each other. The mother of a 12-year-old Syrian girl with a speech impairment noted, 'I moved to this village because people are nice... My daughter attends the school and she is building good friendships'.

However, research in the rural governorate of Mafraq revealed a different experience, highlighting a lack of support from government schools for Jordanian children with disabilities; indeed, they did not accept children with mobility impairments at all. Parents of adolescents with disabilities reported that the school principal had said 'it is a big responsibility-we could not provide protection to your children'. In one remote village where Bedouin communities live, the streets were poorly paved, meaning that adolescents with mobility impairments who needed a wheelchair were unable to move around. The mother of a 13-yearold boy said 'I asked the neighbour's children to push him but his wheelchair broke because the street is full of stones'.

Children with mobility problems did, however, seem to fare better than those with other types of impairment. There is no school for children with hearing or visual impairments in Mafraq, and families reported facing many problems getting an education for their children; as the father of two deaf children explained, 'When my kids reached the age of six, I looked for schools, but there is no school in Mafraq. I sent them to Irbid, but daily I had to pay $10 \mathrm{JOD}$ [Jordanian dinars]. So after two years I stopped sending them, as it was so expensive'. He added that a charity had eventually stepped in to help: 'I heard that a charitable society would accept my kids so at least they now have a place to study'. Similarly, the mother of a girl with a visual impairment noted that she had sent her to a government school' but the principal refused to accept her! After this 1 made a lot of effort to get her into school, but the principal refused to give her the books! Up until 6th grade she went to school but had no books'.

Girls with disabilities in Mafraq were notably more likely to have dropped out of school than boys due to conservative gender norms and tribal pressures. Families were also less likely to send their girls to organisations that provided some educational support. A teacher in one charitable society for children with disabilities explained that this is because the classes are mixed sex, which goes against cultural and religious norms. 'Families will not send their daughters, although we try to convince the parents to send them'. Mafraq is a largely conservative society, structured along tribal lines, in which education for girls is seen as more controversial than in cities like Amman. One mother noted that if my uncles saw my deaf daughter walk in the street, they would make a big problem for me. In our tribe, even healthy girls do not finish secondary school - for girls with disability, it is even more difficult'. 


\section{Stateless Palestinians}

One of the major challenges facing stateless Palestinian adolescents in Jordan is the limited availability of services for those with disabilities. There is no school for adolescents with disabilities in Jerash camp, where many stateless Palestinians live. If they encounter difficulties while learning in mainstream schools, children with hearing or visual impairments often drop out. The closest school to the camp that could accommodate children with hearing impairments was in Salt, around 30 minutes of drive. This school was run by a church, but some parents were concerned about it being run as a boarding facility: 'this school keeps our children in dormitories and allows them to visit their families only at weekends'. Parents were particularly concerned about sending their daughters there, as they felt they would not receive adequate supervision and safety.

Within mainstream schools, adolescents with disabilities face major challenges. Many respondents said that teachers do not pay attention to children with disabilities, and girls with hearing impairments reported being heavily affected by being overlooked by teachers. Five out of the eight girls with hearing problems involved in the research had dropped out of school for this reason. One 16-year-old girl explained, 'She [the teacher] said I have a problem with the English language and I need support. She said I need private lessons, but my family do not have money, and I am worried I will not pass the Tawjihi'.

In Jerash camp, a community centre supervised by the UN Relief and Works Agency for Palestine Refugee in the Near East (UNRWA) provides educational support for children with disabilities, including conducting hearing assessments and providing assistive devices. The centre also runs some classes for adolescents with disabilities who do not attend school. However, it has faced difficulties in paying teachers' salaries, let alone buying specialise equipment. Indeed, adolescents with disabilities reported that they did not attend this centre because of shortage of services there. This was especially the case for adolescents aged 14 and over; one explained, 'No teachers there teach the school curriculum-for example, maths, English, physics, chemistry'. The UNICEF-supported Makani centre at the camp, run by the Islamic Centre, provides education services but only for those with mobility impairments or minor disabilities. One blind 19-year-old girl said 'I went for a few days, but I did not return again as I did not benefit from their education services'.

Adolescents with disabilities in Jerash camp also lacked access to assistive devices such as hearing aids or materials in Braille. Hearing devices were occasionally provided by the rehabilitation centre in the camp, but were not available all the time, and not all adolescents who needed them were able to get them. Another issue was that devices needed maintenance, which was seen as a big problem for the adolescents and their families because the maintenance centre is in Amman; it would cost money and time to get there, so for that reason, some adolescents gave up on the devices and threw them away when they stopped working. However, Gazan adolescents with disabilities also lacked information on how they could access adaptive materials or devices. When asked about Braille, one girl with a severe visual impairment replied 'we did not know about Braille — this is the first I heard about it'. 
Many adolescents with disabilities reported performing poorly compared to their non-disabled peers due to the quality of education available. Parents of adolescents with disabilities also reported that their children did not do well at school-but expressed low expectations of their ability to perform in class. The mother of an 11-year-old boy with mobility impairments said 'I send him to school to pass the time'.

While adolescents with disabilities wanted to be in school, most did not plan to continue their education to secondary or university level. Many girls said that continuing their education depended on their father's approval-and other plans he might have for them. One 15-year-old girl with a disability said, 'I work hard at school to prove to my father that I am a hard worker and to achieve a good school performance so he will let me continue my studies'. A girl with a visual impairment explained 'I am not sure my father will let me continue my study at university'. A 16-year-old girl explained 'the summer vacation is a nightmare for me. Each summer vacation I am stressed all the time, because maybe at any time my father will tell me that this year I will not go to school and he will find someone to marry me. So each year when the summer vacation has passed safely, I feel so happy'.

However, there were some indicators of positive developments in Jerash camp. The Makani centre provides a space where adolescents can build friendships; it is often the only place where girls not in school can meet other girls. One 16-year-old girl said her father made her leave school in the 7th grade: 'It is my father's policy and rule that after a girl finishes 6th grade, then she must stay at home- "there will be no girls in my home dressed in the green (7th grade) uniform!"' She went on to explain: 'I started to attend Makani centre and benefited from their educational support. I put myself forward to take the $10^{\text {th }}$ grade exam from my home. I registered in the class for those who have dropped out of school. When I got my exam results, I found I was ranked first among all the girls. I dream to work in Makani as a facilitator for young children'.

Girls in Jerash camp were particularly vulnerable to violence which affected their access to education because it leads to limits on their mobility. Girls in a focus group in the camp explained that 'One girl last summer was raped by a man on her way from school; many fathers after this event stopped their daughters going to school. All of them [fathers] now became more careful and worry about their daughtersthey blame the girl that she left her friends'. However, boys with disabilities were more likely than their female counterparts to experience inter-peer violence and violence from teachers. A 15-year-old boy in Jerash camp described the atmosphere: 'I hate the school principal and teachers... all time they hold the stick and beat us. The boys in my school are so aggressive. I saw some of them hide sharp tools'.

\section{Syrian Refugees}

GAGE research found notable differences between the educational experiences of refugee adolescents in UNHCR camps and in host communities. In Azraq and Zaatari camps, educational services are generally better than those available to Palestinians in Jerash camp. This is because of the plethora of international organisations active in Jordan since the start of the Syrian civil war, many of them advocating 
for refugees' education rights. Children are also restricted from working in Jordan, which further encourages schooling; as one said, "with nothing else to do, we go to school'. Syrian parents and children were both aware of their right to continue education, even while displaced in Jordan.

There have been some efforts to promote equal access to education for adolescents with disabilities. Within the camps, refugee youth travel a short distance to school and there are no transportation costs, which means that even children with disabilities are usually able to safely make their way there. In Zaatari and Azraq camps, there are several organisations that provide assistance to people with disabilities. One boy who had lost his leg during the conflict in Syria said that Handicap International had provided him with an artificial leg. The Makani centre is also well known in the camps, and some adolescents with disabilities attend its programmes. This is partly because there are no schools for adolescents with severe hearing or visual impairments, which means many of them drop out of mainstream classes. A parent of a Syrian adolescent with a disability noted that "when we came here to Jordan we found that education is important and you can only get a job if you are educated'- a message that many young people appear to have internalised, as many said they would like to go to university.

Syrian refugees living in host communities in Jordan faced greater challenges in accessing education than those in camps. Adolescents with disabilities have the option of attending government-run special schools, but the cost of getting there was often noted as a major obstacle. The cost of transportation was prohibitive for many families, and disability-unfriendly apartment complexes were an additional barrier. A number of caregivers noted that they struggled to attend services with their adolescent child as they lived in a building with multiple flights of stairs. Parents also reported that government schools did not always accept Syrian children. The mother of a 16-year-old Syrian girl with a hearing impairment, living in Irbid, explained the barriers preventing her daughter from attending school: 'She does not attend school, no government school accepted her, and the private schools cost money'. A 17-yearold boy with a disability said 'I stayed at home for one year until my father found an adapted school that was close enough to our house'. While Syrian adolescents in host communities are still able to attend Makani centres in camps, many do not know about it. Just as Jordanians in Mafraq experienced marginalisation from services, so too did Syrian adolescents with disabilities living in the governorate.

Some Syrians who live outside camps live in informal tented settlements (ITSs) rather than in host communities. In one such settlement close to Amman, some adolescents with disabilities were attending schools and going to the Makani centre in the city, but not those with the most severe impairments. None of the adolescents living in this settlement in Mafraq were attending school; those who were physically able, such as those with hearing impairments or mild visual impairments, worked on the farms with their families instead. One 16-year-old girl with a hearing impairment said, 'I do not go to school-I have been working on the farm since I was 10'. Adolescents who cannot do physical work do other types of work at home, as a 16-yearold girl with a visual impairment explained, 'I stay at home cook for my family and uncles when they work in the farm'. Adolescents who were blind were generally kept at home, neither able to work nor supported to access adapted education. 


\section{Voice and Agency}

\section{Jordanian Adolescents}

The different contexts in which the research with Jordanian adolescents was conducted means that a varied picture emerges of their ability to exercise voice and agency. In Amman city there is good availability of services for young people with disabilities. The Higher Council for the Rights of Persons with Disabilities is based in Amman, and runs club and other activities for adolescents with disabilities. Indeed, because most organisations advocating for disability rights are located in Amman, there are numerous events held there. An 18-year-old boy said, 'I joined a club and participated in many games-I even travelled to other Gulf countries and won a cup'.

In our qualitative research, only in Amman did adolescents with disabilities report inclusive sports activities and other competitions. This is bolstered by the availability of special government-run schools for children with disabilities (such as the schools for children with severe hearing and visual impairments), which actively promote children's voice and agency and encourage their participation in social events and community work outside of school. However, even in Amman, the picture is not completely positive; boys with disabilities in specialist schools reported experiencing high levels of physical violence from their peers, while girls reported being subject to harassment from their community and school peers. This led families to worry about the safety of their children when allowed to go out alone.

In Irbid governorate, there are also high rates of violence perpetrated by children without disabilities against those with disabilities, and there are no organisations targeting support to young people with disabilities in the villages or towns. However, the same social connections that were discussed earlier (in terms of helping adolescents with disabilities receive support in school) can serve to restrict girls' mobility. Because of strong social ties, families are careful to uphold their reputation, and this means ensuring that girls are protected. This often leads to girls being isolated socially and lacking ability to make decisions about how they spend any free time.

In Mafraq, a predominantly Bedouin area, Jordanian girls face similar restrictions on their mobility because of social norms. However, one big difference here is the issue of drugs, which are a huge concern for parents of boys, and so they are now likely to limit their sons' mobility as well. One parent said 'I cannot let my sons go to any place or build friendships because of the risk of drugs-maybe someone will give him pills and he will use them'. Also in Mafraq, there are few organisations for people with disabilities, leading not just to fewer social activities, but also less knowledge about the rights of adolescents with disabilities and available services.

\section{Stateless Palestinians}

The qualitative research with stateless Palestinian adolescents highlighted a significant absence of adolescents with disabilities within extra-curricular activities such as reading competitions, sports and media broadcasts. While they were aware of their rights to participate, adolescents with disabilities reported that they simply did 
not receive invitations to attend such activities. This was especially the case for those with hearing impairments, probably due to the adaptations that would be needed to make these activities accessible; adolescents with mild mobility or visual impairments were more likely to have had the opportunity to participate. However, adolescents felt their families did not see participation in school activities as valuable, with most focussing on improving their children's performance at school. Indeed, this reflects a broader issue in that adolescents with disabilities are not encouraged to make decisions about their lives. Many felt they did not have a voice in family decision-making or problem-solving and could not even make choices about their food and clothes; although for many in Jerash camp, the high levels of poverty render such choices a luxury.

Palestinian adolescents with disabilities tended to be more socially isolated, especially those living in Jerash camp. Girls do not engage in social activities outside the home, and face stronger restrictions on their mobility than do boys with disabilities. One 16-year-old girl with a hearing impairment said, 'My father does not let me visit my aunts or friends - it took a hard conversation but my mother was able to get me permission to visit my grandparents'. In contrast, a 14-year-old boy with a visual impairment commented, 'I play on the street, and went to organisations myself to ask for financial help'. In Jerash camp, girls — regardless of disability status-are generally not allowed a mobile phone: 'We are disconnected from the world. We only hear news about the community from our parents', one girl said. While there are material barriers to girls' ability to exercise agency in Jerash, social norms represent a major challenge for girls who want to participate in their community because of how such norms restrict girls' access to social activities or digital connectivity with peers.

Another major factor constraining the participation of adolescents with disabilities (particularly girls) is the lack of safety in Jerash camp. Girls reported being exposed to verbal harassment by boys and men on the way to school, and expressed fear of men who sell drugs in the street. As a result, girls who reported or spoke up about violence were often then removed from school or prevented from participating in social activities as a measure not only to protect them directly, but to prevent sexualised harassment that would harm the family's reputation. The mother of a 17-year-old girl with a hearing impairment explained 'I will not let her visit her friends in their houses, because we heard one time that a girl from the camp visited her friend and was raped'. Social norms around male power and authority also served to justify violence against girls perpetrated by brothers and uncles, as men are seen as entitled to control girls' lives.

\section{Syrian Refugees}

In Azraq and Zaatari camps, Syrian refugee adolescents with disabilities have relatively better opportunities to exercise voice and agency than Palestinians living in Jerash camp. Each neighbourhood in the camps has a Makani centre, while in Jerash there is just one serving all camp residents. This means that more Syrian refugee adolescents with disabilities than their Palestinian counterparts can access Makani activities (a number of Syrian children with disabilities had mentioned 
their involvement in Makani). General awareness and a supportive environment also means they are more confident in expressing concerns to teachers. UNICEF and other organisations in the Syrian camps have educated children about their participation rights, with more Syrian young people in camps aware of UNICEF's role than Palestinians in Jerash camp. However, boys with disabilities were still subject to physical and verbal abuse by peers, especially on their way to school. In response, Makani had started to provide protection for these boys by sending a teacher to accompany them when walking home, showing the important role played by organisations in promoting greater freedom and protection for adolescents with disabilities.

In Azraq and Zaatari camps, the families of adolescents with disabilities put fewer restrictions on their mobility than those in Jerash camp, including for girls, as social norms among Syrian families are generally less conservative. In Syrian camps, girls or boys with disabilities are allowed to access social media, but this is only possible if their families can afford a phone or other device (so the main barrier here is financial rather than social). Adolescents with disabilities, both boys and girls, are generally able to choose their friends and can spend time with them. One girl aged 12 with a hearing impairment reported playing regularly at her friend's home: 'we prepare good snacks together and we had a birthday party for her'.

For Syrian children with disabilities who live in Amman, there is more freedom to communicate with different people and go to organisations for support. Syrian refugee adolescents in Amman had strong friendships, even more so than those in camps. One girl aged 16 with a mobility impairment said, 'I have daily girls' meetings in front of my house-we start arriving from $6 \mathrm{pm}$ and stay playing, eating and watching people in the streets till 10 or 11 pm!' While in the camps, the Makani centre was a vital point of support, in Amman it was seen as less important, because adolescents had better access to leisure activities and more freedom to spend time with friends. One 13-year-old boy with a visual impairment said, 'daily I play football with children in the neighbourhood, it is an important thing for us-I would be sad if my parents stopped me doing that'. A 14-year-old boy with a hearing impairment noted, 'I do not go to Makani-I work in a supermarket and in the evening I play football'. Syrians in the host community in Amman can also access social media and own mobile phones; one 16-year-old girl with a mobility impairment explained: 'I have Instagram and talk with a 19-year-old boy who is from Palestine. $\mathrm{He}$ is my friend. I cannot imagine my life without the internet'. However, as with Jordanian adolescents, boys were also exposed to violence from peers and teachers in Amman. While girls were not subject to teacher violence, they did feel discriminated against because they were Syrian.

In Irbid city, Syrian adolescents with disabilities have some access to organisational support. All Syrian girls and boys in the qualitative sample reported being involved in social activities and volunteering. A well-known Syrian disability activist lives in Irbid, who has provided a role model for young people to get involved in community work. One girl aged 17 in a wheelchair said, 'I was invited by an organisation to participate in a play. It was a nice thing, I am so happy’. A 17-yearold boy with a mobility impairment stated, 'I participated with a group of people with disabilities in training to learn to make hand-made accessories, and we successfully sold some of them'. Yet Syrian adolescents with disabilities in Mafraq, whose 
families had moved there to do agricultural work, have much less agency. There are no organisations in Mafraq advocating for disability rights, and no services for people with disabilities, so young people with disabilities there lack both organised activities and the free time to engage in 'fun'. A lack of safety also prevents some people in Mafraq wanting to spend time outside. Adolescents with disabilities reported experiencing violence and bullying from peers on their way to school, and discrimination, both from their own families and the community in Mafraq.

\section{Discussion and Implications}

Our findings show that social support (particularly parental support) is vital for adolescents to expand their capabilities around both education and voice and agency, with the former being extremely important for adolescents' capacity to exercise the latter. Among Jordanians in Amman, where adolescents with disabilities are most likely to be in school, mothers often take on the role of activists when it comes to disability issues, connecting with national organisations, community organisations and special schools. They were well informed about laws and policies on disability. As a result, some Jordanian mothers in Amman were advocating for their children's rights and were participating in awareness sessions to help them understand adolescents' physical and psychosocial needs. The mother of a 13-year-old blind girl explained, 'I attended special sessions on the specific issues facing blind children. I benefited a lot from these sessions, and I was able to give my daughter information about her sexuality'. Several mothers said they were inspired by their children and supported them to continue their education.

Yet, while these services are important, access remains mediated by status (refugee or local person). Syrian mothers living in Amman lacked basic information about education, healthcare and economic opportunities for people with disabilities. Some did not know where special schools for children with audio or visual impairments were located; they only knew about medication and assisted living devices.

The picture outside the capital is more mixed. In Irbid, Jordanian mothers did not report having attended any sessions on disability awareness but still expressed support for their children to continue their education. However, Syrian mothers living in Irbid had a better grasp on what services were provided and had attended courses offering support to families with vulnerable adolescents, including parenting classes and recreational activities for parents and young people alike. The Syrian community in Irbid is well connected and some mothers are active in a committee that works to raise awareness of disability issues. Yet, in Mafraq, even supportive mothers were unable to access support and services for their children as these are simply not available there. In Mafraq, Syrian mothers did not know how to communicate with their children or what their needs were. This underlines the importance of service providers engaging with and supporting families of children with disabilities.

In the camps of Jerash, Zaatari and Asraq, there are significant differences in the services available; this impacts approaches to caregiving by Syrian and Palestinian refugees. In Jerash, many families are extremely poor and concerned with daily survival rather than how to best care for their child with a disability. Because Gazan 
Palestinians are stateless, their access to disability services is restricted, which in turn limits their awareness and participation in organised activities. Mothers of children with disabilities in Jerash have little information about services or how to meet their child's needs, manifesting in poor communication with their children, with particular impacts on adolescents with hearing impairments. None of the mothers of deaf children involved in the qualitative or participatory groups in Jerash knew sign language, for example, which limited their information about their child's needs.

For Syrian refugees, the presence of international organisations means that some mothers are more aware of disability rights, particularly in relation to education access. Mothers in the camps knew the main organisations providing services for people with disabilities and also actively searched for more support for their children. However, Syrian and Palestinian mothers both had little information about adolescents' psychosocial needs. They were also unsure about how to communicate with their child about the changes which puberty brings.

GAGE research shows that for adolescents across Jordan, from host and refugee communities, specialist services can do a great deal to promote awareness of the rights of people with disabilities and how to better support them. Having structural support for education through specialist services has a major positive impact on adolescents' ability to achieve in school and on their aspirations and plans for the future. Previous research has drawn attention to the reliance of the Jordanian government on individual schools to institute inclusive learning practices, but observes that there is limited data to support claims about discrimination and stigma (Benson 2020). By taking as our starting point the intersections of marginalisation by age, gender and disability, we have been able to nuance these observations, drawing attention to the ways significant disparities in opportunities and infrastructure in urban and rural areas are compounded by conservative gender norms-creating barriers for girls with disabilities that are very difficult to overcome. These findings also reflect recognition elsewhere in the literature of the particular isolation and marginality facing adolescent girls with disabilities in Jordan, and the urgent need to address both institutional provision and social norms (Presler-Marshall et al. 2020).

\section{Limitations}

Whilst these findings contribute new critical insights into the experiences of adolescents with disabilities in Jordan, the limitations to the study presented and discussed here should also be recognised and addressed. Due to stigma and a lack of services for people with disabilities, especially for Syrian refugees in camps and ITSs, even identifying the sample and inviting participation was challenging. This was particularly the case for identifying and interviewing girls, for whom stigma is amplified by gender and social norms, with families often reluctant to disclose to service providers that they have a disabled daughter.

A notable limitation is that adolescents with intellectual or psychosocial disabilities were not included in the sample for this round of data collection; this would have required specialist training for researchers and adaptation of tools. Funding for these activities was not available at this point, but the researchers hope this will be 
an option for future rounds. Therefore, only adolescents with visual, hearing and mobility impairments participated in the research.

The research also did not include interviews with teachers to understand the service provider perspective, which may have offered greater insights into the drivers of educational exclusion in particular, but permits from the Ministry of Education to interview teachers require a lengthy application process.

Finally, because of families' concerns to protect adolescents with disabilities, we sometimes had to involve caregivers in the interview process; in the case of young people with hearing impairments, family members were often those who interpreted in sign language. This will have had an impact on what adolescents were able and willing to disclose. However, this compromise was made because bringing in professional sign interpreters would not necessarily have worked as a means of promoting communication, as adolescents did not always understand standard sign language, instead often used family-adapted methods of communication.

\section{Conclusions}

By exploring adolescents with disabilities' experiences of education and exercising voice and agency in a context of displacement like Jordan, this article has identified the importance of social support and organisations in enabling and constraining their capabilities. Adolescents with disabilities face various barriers in accessing education, but support from family and school plays an important role in promoting aspirations. Conversely, social isolation of adolescents with disabilities, and their limited access to broader support systems like peer groups, constrains their participation and capacity to exercise voice and agency, both at home and within their communities. Bullying and peer violence were also reported by many adolescents with disabilities, yet isolation makes them feel less able to reach out for help or know to whom they can turn.

This article also shows that gender norms, nationality and citizenship, and rural-urban divides profoundly affect the experiences of adolescents with disabilities in Jordan. There are far fewer services available in rural areas, and stigma remains prevalent. These challenges intersect to reinforce marginality. Adolescent girls in Jordan, of all nationalities and in all areas, experience high levels of social isolation due to restrictions on their mobility; for adolescent girls with disabilities, these restrictions are even more rigid and difficult to negotiate.

Strategies to support adolescents with disabilities to expand their capabilities around education and voice and agency must address these complex and nuanced factors that are driving the poor outcomes identified across these two domains. The pathways discussed in this article reflect the social nature of disability and the key role that discrimination plays in restricting capabilities, and thus the importance of overcoming these at both an individual and structural level. Parental support for adolescents with disabilities to overcome the challenges they face is essential, and this can be promoted through engaging with parents on how best to support their children with disabilities. Given the significant role of communities in creating an enabling and supportive environment, it is also essential to challenge community norms 
that marginalise adolescents with disabilities. Finally, there is a need to address the fragmented service provision and limited disability-responsive infrastructure (particularly in rural areas) that can help adolescents with disabilities to participate in their communities and access schooling. More robust social protection systems, with linkages between economic support and referral pathways to complementary protection and psychosocial services, can help to ensure that disability does not prevent adolescents achieving and living lives that they value.

Funding Funding was provided by Department for International Development.

\section{Declarations}

Conflict of interest On behalf of all authors, the corresponding author states that there is no conflict of interest.

Open Access This article is licensed under a Creative Commons Attribution 4.0 International License, which permits use, sharing, adaptation, distribution and reproduction in any medium or format, as long as you give appropriate credit to the original author(s) and the source, provide a link to the Creative Commons licence, and indicate if changes were made. The images or other third party material in this article are included in the article's Creative Commons licence, unless indicated otherwise in a credit line to the material. If material is not included in the article's Creative Commons licence and your intended use is not permitted by statutory regulation or exceeds the permitted use, you will need to obtain permission directly from the copyright holder. To view a copy of this licence, visit http://creativecommons.org/licen ses/by/4.0/.

\section{References}

Abu-Hamour, B., and H. Al-Hmouz. 2014. Special education in Jordan. European Journal of Special Needs Education 29 (1): 105-115.

Alkire, S., J. Foster, S. Seth, M.E. Santos, J.M. Roche, and P. Ballon. 2015. Multidimensional poverty measurement and analysis. Oxford: Oxford University Press.

AlMakhamreh, S.S., H.T. AlHadidi, and A.M. AlBakar. 2015. Social work students field training as an opportunity to develop best practice in disabilities: The case of Jordan. European Journal of Social Work 18 (5): 756-769.

Al-Zyoudi, M. 2006. Teachers' attitudes towards inclusive education in Jordanian schools. International Journal of Special Education 21 (2): 55-62.

Anastasiou, D., and C. Keller. 2011. International differences in provision for exceptional learners. In Handbook of special education, ed. J.M. Kauffman and D.P. Hallahan, 773-787. London: Routledge.

Avramidis, E., and B. Norwich. 2002. Teachers' attitudes towards integration/inclusion: A review of the literature. European Journal of Special Needs Education 17 (2): 129-147.

Battle, D.E. 2015. Persons with communication disabilities in natural disasters, war, and/or conflict. Communication Disorders Quarterly 36 (4): 231-240.

Baylies, C. 2002. Disability and the notion of human development: Questions of rights and capabilities. Disability \& Society 17 (7): 725-739.

Benson, S. 2020. The evolution of Jordanian special education policy and practice. FIRE: Forum for International Research in Education 6 (1): 102-121.

Bešić, E., L. Paleczek, and B. Gasteiger-Klicpera. 2020. Don't forget about us: Attitudes towards the inclusion of refugee children with(out) disabilities. International Journal of Inclusive Education 24 (2): 202-217.

Braithwaite, J., and D. Mont. 2009. Disability and poverty: A survey of World Bank poverty assessments and implications. ALTER European Journal of Disability 3: 219-232. 
Burchardt, T. 2004. Capabilities and disability: The capabilities framework and the social model of disability. Disability \& Society 19 (7): 735-751.

Burge, P., H. Quellette-Kuntz, and N. Hutchinson. 2008. A quarter century of inclusive education for children with intellectual disabilities in Ontario: Public perceptions. Canadian Journal of Educational Administration and Policy 87 (3): 1-22.

Culbertson, S., and L. Constant. 2015. Education of Syrian refugee children: Managing the crisis in Turkey, Lebanon and Jordan. Santa Monica, CA: RAND.

El-Zraigat, I., and Y. Smadi. 2012. Challenges of educating students who are deaf and hard-of-hearing in Jordan. International Journal of Humanities and Social Science 2 (8): 1-9.

GAGE consortium. 2019. GAGE conceptual framework, 2nd ed. London: Gender and Adolescence: Global Evidence.

GBD 2017 Child and Adolescent Health Collaborators. 2019. Diseases, injuries, and risk factors in child and adolescent health, 1990 to 2017: Findings from the Global Burden of Diseases, Injuries, and Risk Factors 2017 Study. JAMA Pediatrics 173 (6): e190337.

Hashemi, G., H. Kuper, and M. Wickenden. 2017. SDGs, inclusive health and the path to universal health coverage. Disability and the Global South 4 (1): 1088-1111.

Humanity \& Inclusion and iMMAP. 2018. Removing barriers: The path towards inclusive access. Disability assessment among Syrian refugees in Jordan and Lebanon. Jordan Report 2018. Humanity \& Inclusion and iMMAP.

INEE. 2014. Mapping the education response to the Syrian Crisis. International Network for Education in Emergencies. https://reliefweb.int/report/syrian-arab-republic/mapping-education-respo nse-syrian-crisis

Ingstad, B., and A. Eide. 2011. Disability and poverty: A global challenge. Bristol: Policy Press.

Jabbar, S.A., and H.I. Zaza. 2014. Impact of conflict in Syria on Syrian children at the Zaatari refugee camp in Jordan. Early Child Development and Care 184 (9-10): 1507-1530.

Jones, L., M.A. Bellis, S. Wood, K. Hughes, E. McCoy, L. Eckley, G. Bates, C. Mikton, T. Shakespeare, and A. Officer. (2012). Prevalence and risk of violence against children with disabilities: A systematic review and meta-analysis of observational studies. Lancet, 380: 899-907. https://doi.org/10. 1016/S0140-6736(12)60692-8.

Jones, N., S. Baird, E. Presler-Marshall, A. Malachoswka, K. Kilburn, B. Abu Hamad, A. Essaid, W. Amaireh, J. Sajdi, K. Banioweda, T. Alabbadi, S. Alheiwidi, Q. Ashareef, S. Altal, W. Kharabsheh, H. Abu Taleb, M. Abu Azzam, and B. Abu Hammad. 2019. Adolescent well-being in Jordan: Exploring gendered capabilities, contexts and change strategies. A synthesis report on GAGE Jordan baseline findings. London: Gender and Adolescence: Global Evidence.

Jones, N., E. Presler-Marshall, and M. Stavropoulou. 2018. Adolescents with disabilities: Enhancing resilience and delivering inclusive development. London: Gender and Adolescence Global Evidence.

Male, C., and Q. Wodon. 2017. The price of exclusion: Disability and education. Disability gaps in educational attainment and literacy. New York: World Bank.

Marcus, R., and C. Harper. 2015. Social norms, gender norms and adolescent girls: A brief guide. London: ODI.

Mitra, S. 2006. The capability approach and disability. Journal of Disability Policy Studies 16 (4): 236-247.

Mustafa, S., E. Melonashi, F. Shkëmbi, K. Besimi, and N. Fanaj. 2015. Anxiety and Self-esteem among University Students: Comparison between Albania and Kosovo. Procedia - Social and Behavioral Sciences. 205: 189-194. https://doi.org/10.1016/j.sbspro.2015.09.057.

Palmer, M. 2011. Disability and poverty: A conceptual review. Journal of Disability Policy Studies 21 (4): 210-218

Patton, G.C., S.M. Sawyer, J.S. Santelli, D.A. Ross, R. Afifi, N.B. Allen, M. Arora, P. Azzopardi, W. Baldwin, C. Bonell, R. Kakuma, E. Kennedy, J. Mahon, T. McGovern, A.H. Mokdad, V. Patel, S. Petroni, N. Reavley, K. Taiwo, J. Waldfogel, D. Wickremarathne, C. Barroso, Z. Bhutta, A.O. Fatusi, A. Mattoo, J. Diers, J. Fang, J. Ferguson, F. Ssewamala, R.M. Viner. 2016. Our future: a Lancet commission on adolescent health and wellbeing. Lancet 387 (10036): 2423. https://doi.org/ 10.1016/S0140-6736(16)00579-1

Pearce, E. 2015. 'Ask us what we need': Operationalising guidance on disability inclusion in refugee and displaced persons programmes. Disability and the Global South 2 (1): 460-473.

Pisani, M., and S. Grech. 2015. Disability and forced migration: Critical intersectionalities. Disability and the Global South 2 (1): 421-441. 
Presler-Marshall, E., N. Jones, and K.B. Odeh. 2020. 'Even though I am blind, I am still human!': The neglect of adolescents with disabilities' human rights in conflict-affected contexts. Child Indicators Research 13 (2): 513-531.

Rohwerder, B. 2017. Disability Inclusive Humanitarian Response. Humanitarian Learning Centre (HLC) Operational Practice Paper 1. Brighton: HLC.

Scior, K. 2011. Public awareness, attitudes and beliefs regarding intellectual disability: A systematic review. Research in Developmental Disabilities 32 (6): 2164-2182.

Skinner, M. 2014. The impact of displacement on disabled, injured and older Syrian refugees. Forced Migration Review 47: 139-140.

Srivastava, M., A. de Boer, and S.J. Pijl. 2013. Inclusive education in developing countries: A closer look at its implementation in the last 10 years. Educational Review 67 (2): 179-195.

Thompson, S. 2020. Disability inclusive development: Jordan situational analysis version II June 2020. Brighton: Institute of Development Studies and Inclusive Futures.

UN Convention on the Rights of Persons with Disabilities (UNCRPD). 2006. Convention on the rights of persons with disabilities. https://www.un.org/development/desa/disabilities/convention-on-therights-of-persons-with-disabilities.html

Vilchinsky, N., S. Werner, and L. Findler. 2010. Gender and attitudes toward people using wheelchairs: A multidimensional perspective. Rehabilitation Counselling Bulletin 53 (3): 163-174.

World Health Organization (WHO) and World Bank. 2011. World report on disability. Geneva: WHO.

Yeo, R., and K. Moore. 2003. Including disabled people in poverty reduction work: 'Nothing about us, without us.' World Development 31 (3): 571-590.

Publisher's Note Springer Nature remains neutral with regard to jurisdictional claims in published maps and institutional affiliations. 